\title{
Ensino de Computação de forma Interdisciplinar com Português: Um Relato de Experiência do PIBID
}

\author{
Higor R. M. Santos ${ }^{1}$, José C. F. Barbosa ${ }^{2}$, Dênis de G. Marques ${ }^{3}$ e Poliana S. de \\ Queiroz $^{4}$ \\ Universidade de Pernambuco, Campus Garanhuns (UPE), \\ CEP 55.294-902 - Garanhuns - PE - Brasil \\ higor.monteiro@upe.br, josecarlosfelix8@gmail.com, \\ denisgm101@hotmail.com e poliana.santos.queiroz@gmail.com
}

\begin{abstract}
This paper describes an experience of the PIBID scholarship holders of the Graduating in Computing and Pedagogy of the University of Pernambuco. The project aims to develop interdisciplinary activities in order to involve concepts of Computer Science, concepts of Informatics and contents of the Portuguese according to the needs of the students. According to the results, it was possible to perceive the satisfaction and the positive effect of the project with all steakholders. As contributions, the pibidians taught Computing in basic education, the students of the school used and developed software and the Portuguese teacher was benefited with a learning object.
\end{abstract}

Resumo. Este artigo descreve um relato de experiência vivenciado pelos bolsistas do PIBID de Licenciatura em Computação e Pedagogia da Universidade de Pernambuco. O projeto teve como objetivo desenvolver atividades interdisciplinares de forma a envolver conceitos da Ciência da Computação, noções de Informática e conteúdos da disciplina de Português conforme as necessidades dos alunos. De acordo com os resultados, foi possivel perceber a satisfação e o efeito positivo do projeto em relação a todos os envolvidos. Como contribuições, os pibidianos lecionaram Computação na educação básica, os alunos utilizaram e desenvolveram softwares educativos e o professor de português foi beneficiado com um objeto de aprendizagem.

\section{Introdução}

Com a utilização cada vez mais frequente das tecnologias digitais de informação e comunicação - TDIC, estamos mergulhados em uma sociedade denominada sociedade da informação, as crianças da atualidade já nascem mergulhadas nesse mundo tecnológico e seus interesses e padrões de pensamento já fazem parte desse universo [BRANDÃO, SELVA E COUTINHO 2006]. Com esses avanços significativos, as tecnologias

\footnotetext{
${ }^{1}$ Mestre e Doutorando em Ciência da Computação pela UFPE. Professor do curso de Licenciatura em Computação da UPE - Campus Garanhuns e desenvolve pesquisas e projetos envolvendo software educativo e ensino de Computação.

${ }^{2}$ Aluno do curso de Licenciatura em Computação da UPE - Campus Garanhuns e bolsista do Programa Institucional de Bolsas de Iniciação à Docência (PIBID).

${ }^{3}$ Aluno do curso de Licenciatura em Computação da UPE - Campus Garanhuns e bolsista do Programa Institucional de Bolsas de Iniciação à Docência (PIBID).

${ }^{4}$ Licenciada em Pedagogia pela UPE - Campus Garanhuns e já foi bolsista do Programa Institucional de Bolsas de Iniciação à Docência (PIBID).
} 
presentes nas escolas também tendem a evoluir e desempenhar um papel importante no processo de ensino e aprendizagem.

Nesse contexto, o ensino de conceitos de Computação nas escolas é essencial para alimentar o raciocínio computacional das crianças, pelo seu caráter transversal às demais ciências, para formar cidadãos críticos a viverem num mundo cada vez mais globalizado [NUNES 2011]. Umas das formas de incluir os conceitos de Computação no ensino é o desenvolvimento do pensamento computacional, que consiste em desenvolver a lógica, a solução ideal e capacidade de dedução e conclusão. Segundo Wing (2006), o pensamento computacional é o método que utiliza fundamentos e técnicas da Ciência da Computação para solução de problemas.

Conforme ressaltado nos Parâmetros Curriculares Nacionais [BRASIL 1999], o mundo contemporâneo exige novas formas de se ensinar, aliadas à incorporação de recursos tecnológicos e computacionais. De acordo com Valente (1997), a atividade pedagógica com o uso do computador pode ser feita tanto a fim de continuar transmitindo a informação para o aluno quanto para criar condições para que o aluno construa seus conhecimentos por meio da criação de ambientes de aprendizagem que incorporem o uso do computador. Para tanto, faz-se necessária à formação de professores especializados em Computação, da mesma forma como é necessária à formação de professores de matemática, de língua portuguesa, de ciências, etc.

Diante dessa necessidade, o curso de Licenciatura em Computação tem como papel formar profissionais com a capacidade de ensinar computação, desenvolver softwares educativos, administrar ambientes em EAD (educação a distância). Tendo em vista que o Licenciado em Computação abarca em sua formação tanto o desenvolvimento e a aplicação de tecnologia como o ensino da Ciência da Computação, o mesmo tem total autonomia em atuar de forma efetiva em escolas de ensino básico, médio e técnico, como também em empresas, etc. No entanto, não existe um espaço para esses profissionais atuarem nas escolas, pois ainda não existe um currículo que contém a Ciência da Computação como uma disciplina na educação básica.

Com a inclusão do Programa Institucional de Bolsas de Iniciação à Docência (PIBID) de Computação nas escolas, pode-se efetivar a aplicação necessária dos conceitos de Computação aos estudantes. Além dos licenciandos em Computação, participou deste projeto estudantes do curso de licenciatura em Pedagogia de forma interdisciplinar. Nesse contexto, o presente trabalho foi desenvolvido na Escola Professor José Ferreira Sobrinho, no $9^{\circ}$ ano do ensino básico. O objetivo principal deste projeto foi desenvolver atividades interdisciplinares de forma a envolver conceitos da Ciência da Computação, noções de Informática e conteúdos da disciplina de Português de acordo com as necessidades dos alunos.

O artigo é categorizado conforme as seguintes seções: seção 2 apresenta os trabalhos relacionados, seção 3 apresenta a metodologia, seção 4 apresenta os resultados e discussões, na seção 5 as conclusões e, por fim, as referências utilizadas.

\section{Trabalhos relacionados}

Além da experiência descrita neste trabalho, diversos autores já publicaram trabalhos sobre a abordagem e aplicação do pensamento computacional na educação básica, bem como experiências relacionadas ao PIBID de Computação. A seguir, são discutidos alguns desses trabalhos.

Lima e De Sousa (2015), apresentam a experiência de alunos da Universidade Federal Rural da Amazônia (UFRA) que são bolsistas do Programa Institucional de 
Bolsas de Iniciação à Docência (PIBID). Foi realizado um curso com alunos do $5^{\circ}$ ano do ensino fundamental em uma escola pública em Belém-PA. Nele, foram elaboradas atividades inerentes aos conceitos de introdução ao raciocínio lógico e algoritmo, onde foi ministrado com os computadores da sala de Informática por meio da ferramenta "Portugol IDE". A experiência no projeto proporcionou aos bolsistas a oportunidade de estabelecer contato com o ambiente escolar e contribuiu para melhorar a aprendizagem dos alunos nas disciplinas básicas de Português e Matemática.

Rodriguez et al. (2015) relatam experiências obtidas em um projeto que incluiu ferramentas digitais em escolas. Os alunos que participaram do projeto desenvolveram algoritmos usando o Scratch. Conforme os autores, o pensamento computacional ajudou a ampliar a capacidade de resolução de problemas dos alunos através de atividades lúdicas e os discentes demonstraram interesse em dar continuidade às atividades de programação.

Silva et al. (2011) relatam uma experiência que consistiu em ensinar conceitos de Ciência da Computação no ensino médio, introduzindo noções de algoritmos de forma interdisciplinar com música e a robótica. O conceito de algoritmo foi abordado com o instrumento musical pandeiro, a sequência de passos para realizar a melodia representou as instruções e passos que um algoritmo possui. Para relacionar com algoritmos computacionais foi utilizada a robótica com o Robô Lego Mindstorms NXT.

No trabalho de Barbosa et al. (2015), bolsistas do PIBID do curso de Licenciatura em Computação promoveram gincana em escolas estaduais da cidade de Rio Tinto na Paraíba, com o intuito de ensinar conceitos computacionais para alunos do ensino médio, através de atividades de computação desplugada do livro Computer Sciense Unplugged.

Ao examinar esses trabalhos, pode-se afirmar que o PIBID interdisciplinar de Licenciatura em Computação e Pedagogia da Universidade de Pernambuco teve como diferencial aproximações entre espaços escolares, desenvolvimento de um objeto de aprendizagem e uma aprendizagem colaborativa da Ciência da Computação. Além de uma proposta pedagógica pensada a partir do diálogo e intensa imersão no cotidiano dos alunos, o desenvolvimento do projeto contribuiu para o desenvolvimento e disseminação do pensamento computacional e com a utilização de plataformas de programação pelos alunos da Educação Básica.

\section{Metodologia}

Desenvolvido entre agosto e dezembro de 2016, o projeto relatado aqui teve como intuito explorar e trabalhar recursos, conceitos e práticas computacionais para apoiar uma aprendizagem lúdica e efetiva no ambiente escolar juntamente com a disciplina de Português. A escolha pela disciplina de Português aconteceu após reuniões entre o coordenador institucional do PIBID e a diretoria da escola. Além da necessidade de inovar no ensino de Português, o professor demonstrou interesse em trabalhar em conjunto com os pibidianos de licenciatura em Computação. Nesse aspecto, o projeto foi organizado conforme as fases listadas a seguir.

Inicialmente, foi realizada uma diagnose ${ }^{5}$ na escola com 26 alunos no $9^{\circ}$ ano por meio de um questionário para poder identificar o nível de conhecimento de Computação da turma conforme a utilização de meios eletrônicos e digitais no cotidiano, uso de meios tecnológicos dentro do âmbito escolar e como essa imersão poderia melhorar o ensino, dentro e fora da escola.

\footnotetext{
${ }^{5}$ Questionário de diagnose - https://goo.gl/forms/z58SD12p5SqxcdOG2
} 
Em seguida, definiu-se um calendário de atividades baseado em conteúdos que identificamos ser mais significativo para os alunos. Ressalta-se que o calendário foi construído de forma versátil de forma a poder acrescentar, retirar ou trocar a data da realização de boa parte das aulas de acordo as necessidades que eram identificadas no decorrer da vivência do projeto. Essa decisão foi tomada com base em experiências passadas, pois a maioria dos alunos da escola não têm habilidades com o uso de computadores (teclado e mouse), bem como softwares básicos. As principais atividades do projeto foram: Coleta de dados e Desenvolvimento do plano de ensino; Alterações no plano de ensino e conhecimento do local de ensino; Aulas específica sobre Computação; Aulas interdisciplinares sobre o pacote Microsoft Office; Desenvolvimento dos pilares do pensamento Computacional; Construção de princípios da programação; Desenvolvimento e finalização projeto.

No desenvolvimento dos planos de aula, foram planejadas aulas dos seguintes conteúdos de Computação: Laço de repetição, pensamento computacional, estrutura de decisão e estruturas condicionais que pudessem ser vivenciados de forma interdisciplinar com o conteúdo de Crase ligado a disciplina de Português, mas que também trouxesse algo significativo principalmente para a área de Computação. A construção das aulas foi pensada para serem aplicadas no laboratório de informática, mas também serem aplicadas dentro da sala de aula de forma desplugada. A Computação Desplugada consiste em ensinar os fundamentos da computação, através de atividades, sem o uso do computador [Bell et al. 2011].

Em seguida, foi planejado e desenvolvido pelos pibidianos um Objeto de Aprendizagem (OA). Um Objeto de Aprendizagem, segundo o Comitê de Padronização das Tecnologias de Aprendizagem (LTSC), é definido como "qualquer entidade digital ou não digital que pode ser utilizada, reutilizada ou referenciada durante o aprendizado apoiado pela tecnologia" [IEEE 2002]. Tarouco (2003), traz também uma definição do que é um Objeto de Aprendizagem. Segundo ela, "Objetos educacionais podem ser definidos como qualquer recurso, suplementar ao processo de aprendizagem, que pode ser reusado para apoiar a aprendizagem".

Mesmo com a existência e disponibilidade de vários OA, optou-se por desenvolver um OA que estivesse relacionado de forma mais intensa com os alunos e com a comunidade na qual o projeto foi desenvolvido. Levou-se em consideração alguns critérios no desenvolvimento do jogo, tais como: Documentação (Game Design) que diz respeito ao material que acompanha o software e descreve informações sobre a ferramenta desenvolvida; Currículo refere-se ao conteúdo previsto para o desenvolvimento de atividades escolares; Aspectos didáticos, subdivididos em clareza dos conteúdos, assimilação e acomodação, avaliação do aprendizado e tratamento do erro.

Por fim, aplicou-se um questionário ${ }^{6}$ final com os alunos que participaram do desenvolvimento do projeto com a intenção de verificar se a utilização dos softwares educativos auxiliou na compreensão dos assuntos trabalhado nas disciplinas e a satisfação deles quanto ao ensino dos conceitos de Computação.

É importante ressaltar que um aluno de pedagogia participante do PIBID realizava o acompanhamento e ao final de cada aula, juntamente com o professor da disciplina de português, avalia o desempenho e oferecia feedbacks de melhoria, bem como um suporte pedagógico aos licenciados em Computação. Esse desempenho era avaliado mediante alguns aspectos pedagógicos e indicadores de atividades docentes criados pelo

\footnotetext{
${ }^{6}$ Questionário final - https://goo.gl/forms/gMbMpVMOMUqJCg4J2
} 
VI Congresso Brasileiro de Informática na Educação (CBIE 2017)

Anais dos Workshops do VI Congresso Brasileiro de Informática na Educação (WCBIE 2017)

licenciando de Pedagogia ${ }^{7}$ baseado em Schö (1983), o qual afirma que esse tipo de reflexão permite que os professores se assumam como investigadores da própria prática docente.

\section{Resultados e Discussão}

Esta seção tem o intuito de apresentar e discutir os resultados alcançados com a aplicação do projeto. Conforme descrito na seção anterior, a primeira etapa do trabalho foi a diagnose. Com base na análise do questionário, foi possível reconhecer que os meios tecnológicos presentes na escola não eram utilizados de maneira a beneficiar o aluno e, quando eram utilizadas, eram de forma mnemônica. A tecnologia presente na escola não era utilizada como ferramenta pedagógica, deixando de contribuir didaticamente com o conhecimento escolar. Mesmo a escola possuindo laboratório de informática, a falta do uso de novas mídias não desafiava professores e alunos a adotarem uma postura mais colaborativa na mediação dos conteúdos em sala de aula.

Diante das respostas dadas pelos alunos, percebeu-se que a tecnologia fazia parte da rotina da maior parte da turma através de celulares, tablets, computadores etc, mas todos fora do ambiente escolar. Ao chegarem na escola, as novas tecnologias deixavam de fazer parte do cotidiano do aluno mesmo que pudessem ser usadas, dando lugar ao caderno e ao quadro branco.

Com essa carência, falta de orientação didática e com a necessidade de os alunos fazerem a utilização desses meios tecnológicos, percebeu-se a necessidade de desenvolver práticas educacionais que pudessem se utilizar ou não de ferramentas tecnológicas para desenvolver o pensamento computacional de forma interdisciplinar. Para gerar um alinhamento entre os alunos sobre o manuseio com computador e alguns softwares básicos, planejou-se inicialmente utilizar editores de texto, apresentações e planilhas.

Para o desenvolvimento dessa atividade, foi escolhido o pacote Microsoft Office, sendo o mesmo o mais utilizado e prático. Conforme uma das demandas da professora de Português, o desenvolvimento do conteúdo foi planejado para alcançar a interdisciplinaridade, onde as construções utilizando as ferramentas apresentadas na qual tiveram como finalidade a construção de resumos e apresentação de seminários abordando os temas crase e conjugação verbal, tendo como assunto principal a crase, definido pela professora de Português.

O desenvolvimento de atividades para se trabalhar o Pensamento Computacional aconteceu de forma lúdica e dinâmica. Os alunos interagiram e participaram das discussões sobre os quatro pilares do Pensamento Computacional: Decomposição, Reconhecimento de Padrões, Abstração e Algoritmo. A demonstração desses pilares aconteceu de maneira expositiva, porém em cada um dos pilares foi apresentada uma atividade desplugada relacionada. Com a finalidade de relacionar os conhecimentos à realidade dos alunos, foi destacada a importância e o uso do pensamento Computacional durante a vida escolar e no dia a dia. Sendo o Pensamento Computacional uma habilidade fundamental para todos, o mesmo não está ligado somente a resolução de problemas complexos mas se propõe a desenvolver em termos de habilidades e competências a projeção de sistemas, a compreensão de comportamento humano, a capacidade de reformular um problema, de planejar, aprender, pesquisar é pensar em múltiplos níveis de abstração.

\footnotetext{
${ }^{7}$ Aspectos pedagógicos e indicadores de atividades docentes - https://goo.gl/yHDK8h
} 
O desenvolvimento e construção dos conteúdos de programação ocorreu de maneira prática e teórica. A teoria foi desenvolvida de maneira expositiva, construindo exemplos de programação, de forma desplugada, utilizando imagens e exemplos do cotidiano dos alunos. Com a construção teórica de programação, as atividades práticas foram realizadas em forma de desafios. Diante disso, foram aplicadas algumas atividades desplugadas do code.org ${ }^{8}$ que consiste na construção de um fluxograma e um algoritmo, ambos utilizando os conceitos de programação que foram apresentados.

Após a conclusão da parte teórica sobre programação, avançou-se para a prática de programação por meio de softwares. Há vários softwares de programação, como por exemplo, SuperLogo ${ }^{9}$, RoboMind ${ }^{10}$, Light-bot ${ }^{11}$ e a plataforma "Programaê! ${ }^{12 "}$. No desenvolvimento das aulas, optou-se por utilizar o software Scratch ${ }^{13}$ por ser uma ferramenta de sequências animadas com uma interface intuitiva e de fácil compreensão, permitindo-se trabalhar de forma interdisciplinar, o que torna a aprendizagem de programação simples e eficiente. Uma das aulas práticas realizadas pode ser vista na Figura 1.

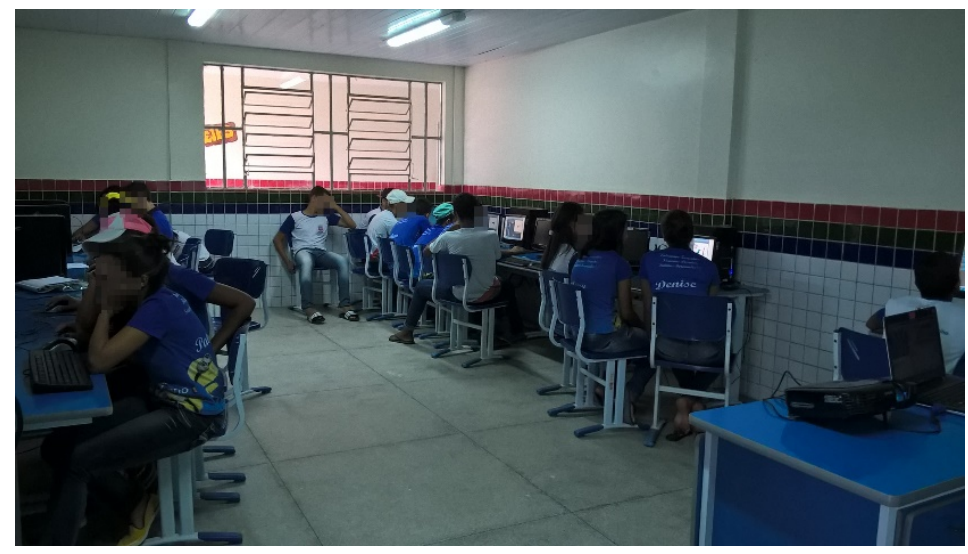

Figura 1. Aula prática.

Como um dos focos principais do PIBID nas escolas é a interdisciplinaridade, foi proposto aos alunos a criação de um trabalho final utilizando a ferramenta Scratch com a intenção de demonstrar algumas regras e exceções do assunto Crase da disciplina de Português. Esse trabalho deveria ser criado no Scratch, de forma livre, podendo ser animações, diálogos ou jogos. Em sua apresentação, deveria conter claramente a descrição dos algoritmos e os pilares do pensamento computacional, como também as regras de Crase utilizadas. Com o desenvolvimento desse trabalho, os alunos puderam exercitar os assuntos tanto em Computação como de Português. Para a construção e a apresentação desse trabalho foram necessárias duas aulas. Pode-se observar na Figura 2 os grupos dos alunos apresentando o resultado dos seus projetos

\footnotetext{
${ }^{8}$ Ver em https://code.org/

${ }^{9}$ Site do Superlogo - http://projetologo.webs.com/slogo.html

${ }^{10}$ Site do Robomind - http://www.robomind.net/pt/

${ }^{11}$ Site do Light-Bot - https://lightbot.com/flash.html

${ }^{12}$ Site do Programaê - http://programae.org.br/

${ }^{13}$ Site do Scratch - https://scratch.mit.edu/
} 
VI Congresso Brasileiro de Informática na Educação (CBIE 2017)

Anais dos Workshops do VI Congresso Brasileiro de Informática na Educação (WCBIE 2017)

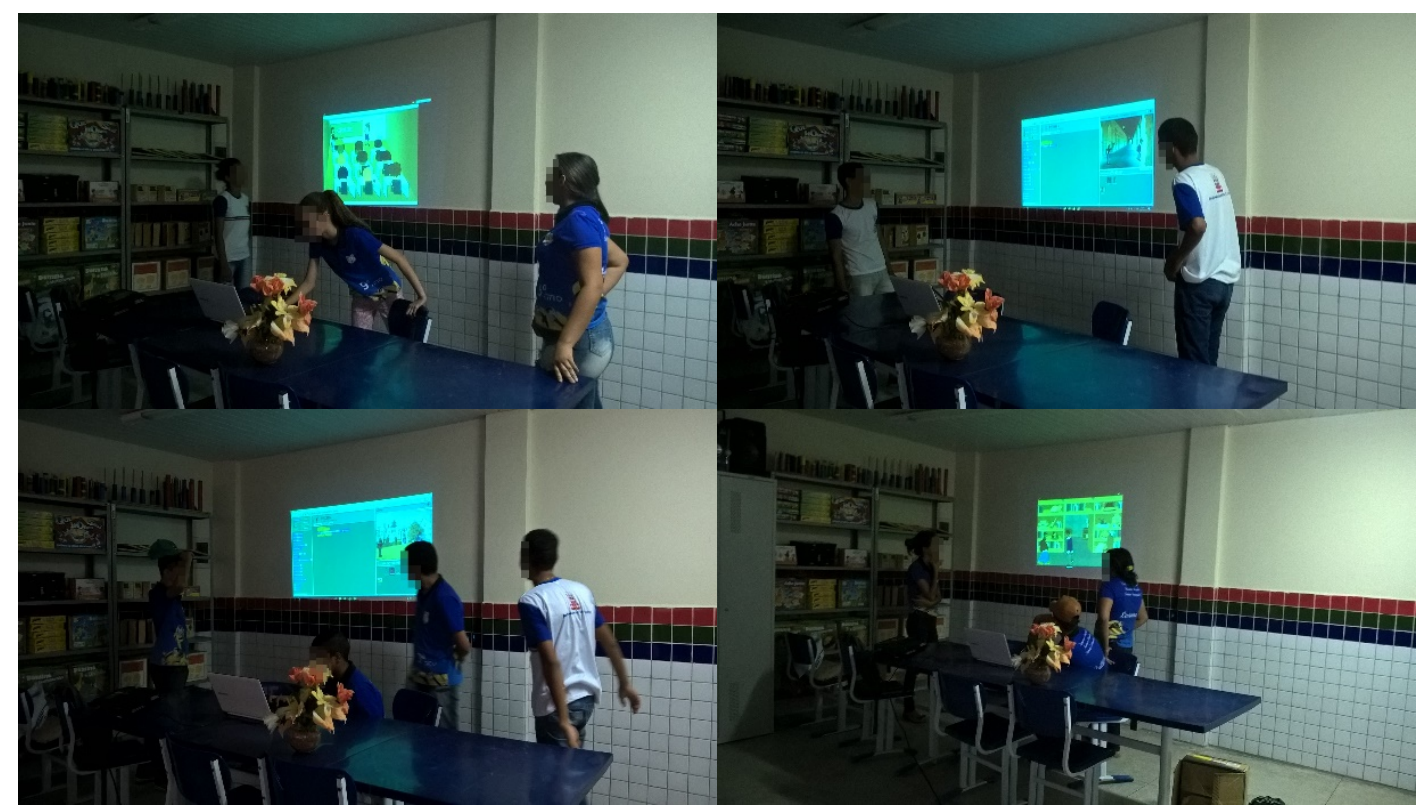

Figura 2. Apresentação dos trabalhos finais dos alunos na ferramenta Scratch.

Para finalizar o projeto, o coordenador do PIBID propôs aos pibidianos de Computação o desenvolvimento de um Objeto de Aprendizagem (OA) para a utilização do professor de português em suas próximas turmas. Como o objetivo principal de um Objeto de Aprendizagem é a utilização do mesmo para construir e desenvolver um conhecimento em específico, analisou-se e decidiu-se construir o OA no mesmo tema que os alunos desenvolveram durante seus projetos finais, que no caso foi a Crase, da disciplina de Português.

O OA desenvolvido pelos pibidianos tem como características um jogo de perguntas e respostas, onde os jogadores vão responder se as frases demonstradas estão empregando o uso da crase de maneira correta ou incorreta. Ao responder se as frases estão corretas ou não, são mostrados feedbacks voltados para auxiliar aos usuários, demonstrando o que ele errou ou acertou como também demonstrando novos exemplos. O OA foi construído utilizando o Scratch e ao longo do seu desenvolvimento foi testado junto aos alunos e o professor da disciplina. Pode-se observar uma de suas telas na Figura 3.

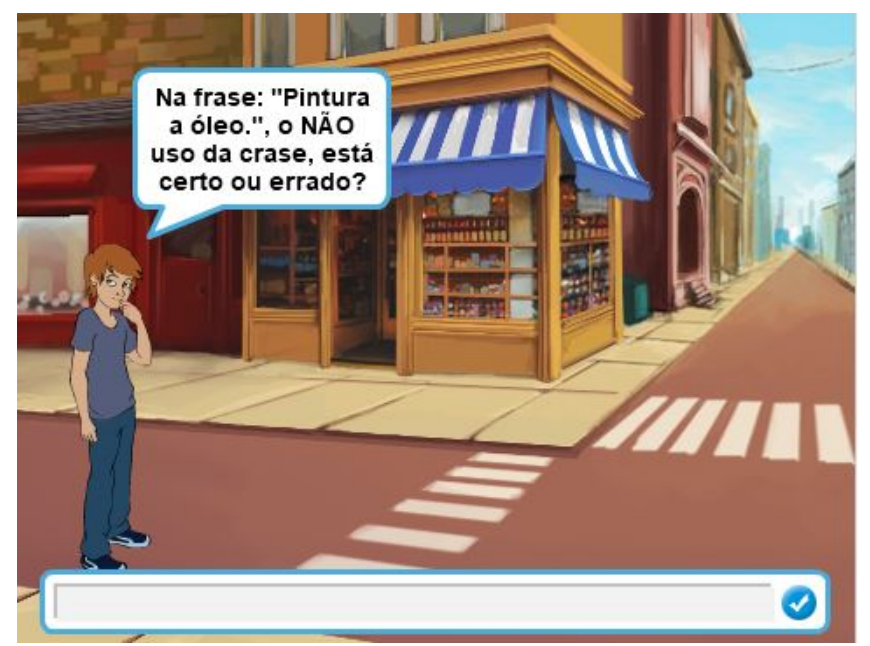

Figura 3. Tela do Objeto de Aprendizagem desenvolvido (Fonte: autores). 
Com o término das atividades na escola, no período de 2016.2, foi realizado um questionário final com os 26 alunos participantes. A partir dos resultados, ficou evidente que a utilização do computador ajudou na compreensão dos assuntos de Português. Conforme as respostas, 21 alunos afirmaram que o computador ajudou na compreensão dos assuntos de Português. O questionário também revelou o interesse dos alunos pela continuidade da utilização do computador nas aulas. Quando questionados o quão bom seria a utilização do computador nas aulas, 24 alunos responderam que o professor teria que usar sim, pois é uma forma diferente de aprender português e os mesmo não ficariam limitados apenas aos livros didáticos.

Em relação a importância do PIBID de Computação nas suas atividades escolares, 10 alunos responderam que foi excelente, 14 alunos classificaram como boa e apenas 1 aluno afirmou que foi insuficiente. Com o desenvolvimento e apresentação do trabalho final dos alunos, foi realizada uma entrevista com a professora e com os alunos. Com base nos resultados, foi possível observar que os alunos conseguiram compreender os assuntos trabalhados, tanto em Computação quanto em Português. Um dos alunos retratou que a utilização dos computadores e a utilização da Computação trouxe uma melhor forma de realizar as atividades, como pode ser visto em sua fala, "porque com a utilização do computador podemos aprender mais do que na sala de aula, pois utilizando o computador prestamos mais atenção do que na sala de aula, com os livros".

\section{Conclusão}

O presente artigo teve como foco principal relatar a experiência da construção e análise dos resultados obtidos com o desenvolvimento de um trabalho de cinco meses numa turma de 9 ano do ensino fundamental junto ao PIBID interdisciplinar de Computação e Pedagogia da Universidade de Pernambuco. O objetivo deste projeto na escola foi desenvolver os conhecimentos dos alunos em Computação, Informática e em Português de forma interdisciplinar.

De acordo com os resultados obtidos e relatados na seção anterior, é possível perceber a satisfação e o efeito positivo do projeto para com todos os envolvidos. Os pibidianos tiveram a oportunidade de lecionar Computação na educação básica de forma planejada ao longo de um semestre e os alunos da escola conheceram pela primeira vez os conceitos básicos da Computação, puderam utilizar softwares existentes e desenvolver seu próprio objeto de aprendizagem de forma interdisciplinar com Português. Além disso, o professor de português foi beneficiado com um objeto de aprendizagem que trabalha $o$ assunto de crase desenvolvido pelos próprios pibidianos. Diante do que foi trabalhado no projeto, é possível afirmar que apenas a inserção de tecnologias não é a solução para os problemas educacionais atuais, é preciso analisar e enxergar como essas tecnologias podem ser utilizadas para auxiliar no processo de aprendizagem.

Como trabalhos futuros, sugere-se utilizar a mesma estrutura do projeto em outras disciplinas da escola, tais como, história, física e química; promover competições entre as turmas com desenvolvimento de objetos de aprendizagem; apresentar mais softwares educativos existentes para auxiliar o processo de ensino e aprendizagem aos professores da educação básica.

\section{Referências}

Almeida, C.; Carvalho, L. (2013) "Licenciatura em Computação: Práticas de Ensino e PIBID como aliadas do processo formativo". Em XIX Workshop de Informática na Escola (WIE, 2013). 
VI Congresso Brasileiro de Informática na Educação (CBIE 2017)

Anais dos Workshops do VI Congresso Brasileiro de Informática na Educação (WCBIE 2017)

Andrade, D., Carvalho, T., Silveira, J., Cavalheiro, S., Foss, L., Fleischmann, A. M., \& Reiser, R. (2013) "Proposta de Atividades para o Desenvolvimento do Pensamento Computacional no Ensino Fundamental". Em Anais do Workshop de Informática na Escola. Maceió - AL.

Barbosa, A,V, S.; Neto, A, F, P.; Oliveira, R, N, R de,; Costa, T, L, S da.; Araújo, A, L, S, O, de.; Costa, F, V, S. (2015). " O ensino de conceitos computacionais para alunos do ensino médio: relato de experiência de uma gincana e das estratégias utilizadas pelos alunos na resolução das atividades desplugadas". Em XXXIII Workshop sobre educação em Informática (WEI 2015).

Bell, T.; Witten, I. e Fellows, M. (2011). "Computer Science Unplugged - Ensinando Ciência da Computação sem o uso do Computador". Tradução de Luciano Porto Barreto, 2011. Disponível em: http://csunplugged.org/. Acesso em 12/05/2017.

Brandão, A., Selva, A., Coutinho, M. (2006). "O trabalho com projetos didáticos: integrando a leitura e a produção de textos". Belo Horizonte: Autêntica.

Brasil. Ministério da Educação. Secretaria de Educação Média e Tecnológica. (1999) "Curriculares Nacionais: Ensino Médio". Brasília.

Dias, K. L., \& Serrão, M. D. L. (2014) “A Linguagem Scratch no Ensino de Programação: Um Relato de Experiência com Alunos Iniciantes do Curso de Licenciatura em Computação”. Em Anais do Workshop de Informática na Escola, Brasília - DF.

Holanda, Maria Nilma. (2009) "O computador como recurso de aprendizagem". Disponível em: < http://www.administradores.com.br/artigos/carreira/o-computadorcomo-recurso-de-aprendizagem/31735/ > . Acessado em: 25/01/2017.

IEEE Learning Tecnology Standard Committee (LTSC). (2005) Em WG12 - Learning Object Metadata. Disponível em <http://ltsc.ieee.org/wg12/> . Acesso em 07-03-2017.

Libâneo, José Carlos. (2009) "Adeus professor, adeus professora? Novas exigências educativas e profissão docente". 6. ed. Disponível em $<$ http://docplayer.com.br/17282282-Adeus-professor-adeus-professora-novasexigencias-educacionais-e-profissao-docente-jose-carlos-libaneo.html $>$. Acessado em: $25 / 01 / 2017$.

Lima, Árllon Chaves; De Sousa, Decíola Fernandes. (2015). "Desenvolvimento do Raciocínio Lógico e Algoritmo Através do Programa Institucional de Bolsas de Iniciação à Docência no Ensino Fundamental”. Em Anais dos Workshops do Congresso Brasileiro de Informática na Educação. p.1379.

Nunes, D. J. (2011). “Ciência da Computação na Educação Básica”. Jornal da Ciência, 09 de setembro.

Rodriguez, C. et al. (2015) "Pensamento computacional: transformando ideias em jogos digitais usando o scratch”. Em Anais do Workshop de Informática na Escola, v. 21, n. 1, p. 62 .

Silva, T. S. C.; Silva, A. S. C.; Melo, J. C. B. (2011) "Ensino de Algoritmos a Nível Médio Utilizando Música e Robótica: Uma Abordagem Lúdica”. Em XIX Workshop sobre Educação em Computação (WEI). Rio Grande do Norte, Brasil.

Tarouco, Liane Margarida Rockenbach; Fabre, Marie-Crhrstine Julie Mascarenhas; Tamusinas, Fabrício Raupp. (2003) "Reusabilidade de objetos educacionais". CINTED. Porto Alegre, v. 1 n. 1, p. 2, fev. 
VI Congresso Brasileiro de Informática na Educação (CBIE 2017)

Anais dos Workshops do VI Congresso Brasileiro de Informática na Educação (WCBIE 2017)

Valente, J. A. (1997) "Visão analítica da Informática na Educação no Brasil: a questão da formação do professor". Em Revista Brasileira de Informática na Educação. RS: Sociedade Brasileira de Computação, ${ }^{\circ} 1$, set.

Weiss, A. L. e Cruz, M. L. R. (1999) “A informática e os problemas escolares de aprendizagem”, 2.ed., Rio de Janeiro.

Wing, J. M. (2006) "Computational thinking. Communications of the ACM". v.49, n.3, p. 33-35. 